\title{
EFICIÊNCIA DE HETERORHABDITIS INDICA IBCB-N05 (RHABDITIDA: HETERORHABDITIDAE) NO CONTROLE DE ALPHITOBIUS DIAPERINUS (COLEOPTERA: TENEBRIONIDAE) SOB COMEDOUROS DE GRANJA AVÍCOLA
}

\section{T.S.C. Rodrigueiro ${ }^{1,2}$, C.M.A. Ginarte ${ }^{1}$, L.G. Leite ${ }^{1}$, F.M. Tavares $^{1}$, R.M. Goulart ${ }^{1}$, F.H.C. Giometti ${ }^{1}$}

${ }^{1}$ Instituto Biológico, Centro Experimental Central, CP 70, CEP 13001-970, Campinas, SP, Brasil. E-mail: entomotaty@gmail.com

\section{RESUMO}

\begin{abstract}
O cascudinho (Alphitobius diaperinus), importante praga de granjas avícolas, se reproduz principalmente sob comedouros do galpão de frango, sendo o inseto beneficiado pela serragem que cobre o pavimento, e pela ração que cai dos comedouros. O presente estudo objetivou avaliar a eficiência do nematóide entomopatogênico Heterorhabditisindica IBCB-n05 no controle de larvas e adultos desse inseto, mediante a aplicação do agente sobre a serragem, sob comedouros do galpão de frango, e também no pavimento de solo batido do galpão. Juvenis infectantes desses nematóides foram aplicados nas dosagens de 0,4; 4 e 40 nematóides por $\mathrm{cm}^{2}$ sobre a serragem. No teste sob comedouros, 12 dias após aplicação, o nematóide nas três dosagens proporcionou, respectivamente, $94 \%, 97 \%$ e $100 \%$ de controle de larvas, e $70 \%, 77 \%$ e $89 \%$ deadultos. Já no teste sobre o solo batido o nematóide proporcionou 15\%,31\% e 35\% de controle de inseto, respectivamente.
\end{abstract}

PALAVRAS-CHAVE: Controle biológico, granja avícola, cascudinho, nematóide entomopatogênico.

EFFICIENCY OF HETERORHADITIS INDICA (NEMATODA: HETERORHABDITIDAE) AGAINST ALPHITOBIUS DIAPERINUS (COLEOPTERA: TENEBRIONIDAE) UNDER POULTRYHOUSE FEEDERS. The lesser mealworm (Alphitobius diaperinus), an important pest of poultry houses, reproduces especially under the chicken feeders, taking advantage of the litter as well as the chicken food dropped from the feeders. The present study aimed to evaluate the efficiency of the entomopathogenic nematode Heterorhabditis indica against larva and adults of this insect by its application on the litter under the feeders in the poultry house, and on the soil ground below the litter. Infective juveniles were applied at the rate of $0.4 ; 4.0$ and 40 nematodes per $\mathrm{cm}^{2}$ on the litter and on the compacted-soil floor. For the test under the feeders, 12 days after the application the nematode provided $94 \%, 97 \%$ and $100 \%$ control of larva, respectively, and $70 \%, 77 \%$ and $89 \%$ of adults, respectively. Concerning the test on the soil, the nematode provided $15 \%, 31 \%$ and $35 \%$ control, respectively.

KEY WORDS: Biological control, poultry farm, lesser mealworm, entomopathogenic nematodes.

\section{INTRODUÇÃO}

Alphitobius diaperinus (Panzer) (Coleoptera: Tenebrionidae) éuma das principais pragas nas granjas avícolas de corte (AxTelL; ARENDS, 1990), sendo mais conhecido popularmentecomocascudinho. Esse coleóptero coloniza o substrato no piso das granjas e os insetos são ingeridos pelas aves em grande quantidade no lugar da ração, trazendo perdas econômicas ao avicultor, pois causam problemas diretos no crescimento e saúde das aves, eindiretos já que podem transmitir diversos patógenos, como vírus, bactérias, fungos e protozoários (De LA CASA et al., 1972; De LA
CASA et al., 1976; Despins et al., 1994; McAllister et al., 1994; McAllister et al., 1995). As larvas desse coleóptero também causam danos nas instalações dos aviários por abrirem túneis no seu material isolante (SAFRIT; AxTELL, 1984).

O Brasil é o terceiro maior produtor e segundo maior exportador de frangos do mundo, o que tem estimulado práticas de manejo como o aumento do número de lotes sobre a mesma cama (devido à escassez da maravalha) e intervalos entre lotes algumas vezes reduzidos, contribuindo assim para o aumento populacional de $A$. diaperinus (CHERNAKILEFFER et al., 2002).

\footnotetext{
${ }^{2}$ Universidade Estadual de Campinas, Instituto de Biologia, Campinas, SP, Brasil.
} 
O uso de inseticidas químicos tem sido um dos métodos empregados para o controle desta praga, no entanto, o custo elevado desses produtos, além dos danos que causam ao meio ambiente, tem levado a procura de alternativas incluindo o controle biológico através do uso de nematóides entomopatogênicos.

Algumas vantagens dos nematóides entomopatogênicos é eles que podem ser produzidos artificialmente em grande escala, podendo ser armazenados por longos períodos (WESTERMAN, 1992), podem ser aplicados pelos métodos convencionais, têm habilidade para buscar seu hospedeiro, são compatíveis com outros inseticidas (KAYA; GAUGLER, 1993), persistem por longos períodos no ambiente natural e não afetam o homem nem outros vertebrados (MILLER; BEDDING, 1982; FERRAZ, 1986). Esses nematóides carregam células de sua bactéria simbionte em seus intestinos e assim que penetram no inseto são liberadas na hemocele causando a morte do hospedeiro por septicemia. O nematóide passa a se alimentar da bactéria, atravessando duas a três gerações, até que o alimento se exaure e milhares de nematóides conhecidos com juvenis infectantes (JIs) deixam o cadáver do inseto em busca de novos hospedeiros (GAUGLer et al., 1997).

Diversos estudos têm avaliado a possibilidade de uso denematóides entomopatogênicos no controle de A. diaperinus (Gedenet al., 1985; SzALANSKi et al., 2004), sendo que alguns testes realizados previamente ao presente estudo demonstraram a patogenicidade do nematóide Heterorhabditis indica Poinar, Karunakar \& David, 1992, isolado IBCB-n05, contra larvas e adultos desse inseto. Nas granjas do Estado de São Paulo, tem-se observado focos de reprodução do cascudinho principalmente sob os comedouros, sendo o inseto beneficiado pela serragem que cobre o pavimento e pela ração misturada a serragem, que cai dos comedouros. Esse inseto empupa no solo e, portanto, tem sido encontrado em maiores populações nas granjas com piso de solo batido comparadas àquelas com pisos cimentados. O presente estudo objetivou avaliar a eficiência de $H$. indica IBCB-n05 no controle de larvas e adultos do cascudinho, $A$. diaperinus, mediante a aplicação sobre a serragem, sob os comedouros de galpão de frango e pavimento de solo batido do galpão.

\section{MATERIAL E MÉTODOS}

OsexperimentosforamrealizadosnaGranjaCláudia situada em Louveira, SP, durante o período de novembro a dezembro de 2003. O nematóide $H$. indica foi isolado a partir de amostra de solo coletada em pomar de citros no Município de Itapetininga, SP, e armazenado com a identificação IBCB-n05 na coleção de nematóides entomopatogênicos do banco de entomopatógenos "OldemarCardimAbreu", pertencenteaoLaboratóriode ControleBiológicodoInstitutoBiológico.Onematóidefoi produzido "in vitro" pelo sistema de esponja (BEDDING, 1984) eutilizado na forma dejuvenil infectante dentro de 10 dias após a sua colheita.

\section{Aplicação sob comedouros}

Foram considerados quatro tratamentos, representados pelo nematóide nas dosagens de 0,$4 ; 4$ e 40 $\mathrm{JI} / \mathrm{cm}^{2}$, e testemunha. Foram utilizadas cinco repetições para cada tratamento, sendo cada repetição representada por uma parcela circular de $28 \mathrm{~cm}$ de diâmetro $\left(615,4 \mathrm{~cm}^{2}\right)$ sobre a camada de serragem cobrindo o piso de um galpão, com $10 \mathrm{~cm}$ de espessura, situada sob comedouro tipo tubular apoiado no substrato. Para cada tratamento, os nematóides foram suspensos em 2 L de água e aplicados sobre a parcela com o auxílio de um regador, tendo sido utilizada somente água na testemunha. Para isso, os comedouros foram retirados e, após a aplicação, retornados novamente no local, apoiados sobre o substrato. A aplicação foi feita dez dias após a liberação dos pintinhos no galpão.

Antes dos tratamentos foi realizada a contagem de adultoselarvasencontradosnasáreas pré-selecionadas para as aplicações. As avaliações foram feitas com seis e doze dias após a aplicação, contando-se o número de insetos (larvas e adultos) vivos do A. diaperinus, encontrados nas parcelas. Para isso, um volume de $120 \mathrm{~mL}$ do substrato foi retirado aleatoriamente de cada parcela comoauxíliodeum Beckerdevidro $(200 \mathrm{~mL})$ eosinsetos presentes no substrato foram contados dentro de uma bandeja plástica $(50 \times 40 \mathrm{~cm})$.

Os dados foram analisados por ANOVA e as médias comparadas pelo teste de Tukey (5\% de probabilidade) no programa SPSS for Windows.

\section{Aplicação no solo batido}

Foram considerados quatro tratamentos, representados pelo nematóide $H$. indica nas dosagens de 0,4; 4 e $40 \mathrm{JI} / \mathrm{cm}^{2}$, e testemunha.Para cada tratamento, os nematóides foram suspensos em $6 \mathrm{~L}$ de água, e foram aplicados também com o auxílio de um regador sobreo soloem umaárea de $1 \mathrm{~m}^{2}$ previamente rastelada para retirar a serragem. Para a testemunha foi utilizada apenas água. Após a aplicação, a serragem foi espalhada de volta nas áreas tratadas. A aplicação foi feita quinze dias após a liberação dos pintinhos no galpão.

Foram consideradas dez repetições em cada área tratada, representadas por 10 tubos PVC $(10 \times 15 \mathrm{~cm})$ distribuídos e enterrados $5 \mathrm{~cm}$ no solo batido, atraves- 
sando toda a serragem. Dentro de cada tubo foram colocadas 15 larvas de $A$. diaperinus no último instar, coletadas nas proximidades. Para impedir a fuga dos insetos, telas de plástico foram colocadas sobre os tubos e amarradas com barbante. Dessa forma, foram dadas condições para que o inseto empupasse no solo, tornando-se alvo fácil para a atuação do nematóide.

A avaliação foi feita com vinte dias após a instalação do experimento, contando-se o número de adultos emergidos dentro de cada tubo. Os dados foram analisados por ANOVA e as médias comparadas pelo teste de Tukey ( $5 \%$ de probabilidade) no programa SPSS for Windows.

\section{RESULTADOS E DISCUSSÃO}

\section{Aplicação sob comedouros}

Aos seis dias da aplicação, o nematóide IBCB-n05 controlou $68 \%, 75 \%$ e $90 \%$ das larvas para as dosagens de 0,$4 ; 4,0$ e $40 \mathrm{JI} / \mathrm{cm}^{2}$, respectivamente (equivalentes a $4,0 \times 10^{7}, 4,0 \times 10^{8} \mathrm{e} 4 \times 10^{9} \mathrm{JI} / \mathrm{ha}$, respectivamente), deacordo com as contagens prévias antes das aplicações dos tratamentos nas áreas selecionadas (Fig. 1). As diferenças entre testemunha e tratamentos indicam oque ocorre coma população decascudinhos ao longo das semanas durante o desenvolvimento de lotes de frangos, isto é, há o aumento da densidade populacional e sobreposição de gerações remanescentes que são favorecidas pelas altas temperaturas no interior dos galpões $(F=4,349 ; \mathrm{gl}=6 ; \mathrm{p}=0,016)$ (Fig. 2). Para adultos, o nível de controle não passou de $40 \%$ (maior dosagem), não ocorrendo diferença significativa na população do inseto entre os diferentes tratamentos, confirmando as diferenças quanto a suscetibilidade entre larvas e adultos já observadas por Gedenetal.(1985). A eficácia de nematóides contra adultos em campo seria associada a sensibilidade às variáveis extremas, como as altas temperaturas no interior dos galpões e a menor suscetibilidade destes indivíduos ( $\mathrm{F}=0,146 ; \mathrm{gl}=6 ; \mathrm{p}=0,931)$ (Fig. 3).

Aos doze dias da aplicação, o nematóide apresentou $94 \%, 97 \%$ e $100 \%$ de controle das larvas para as dosagens de 0,$4 ; 4,0$ e $40 \mathrm{JI} / \mathrm{cm}^{2}$, respectivamente, com diferença significativa entre a testemunha e os tratamentos com nematóide no que se refere à população do inseto $(F=19,113 ; \mathrm{gl}=6 ; \mathrm{p}<0,0001)$ (Fig. 2). Para adultos, o nível de controle aumentou em relação à primeira avaliação, variando de 70 a $89 \%$ para as dosagens de 0,4 a $40 \mathrm{JI} / \mathrm{cm}^{2}$, respectivamente, sem ocorrer, entretanto, diferença significativa entre os tratamentos no que se refere à população do inseto $(\mathrm{F}=1,206 ; \mathrm{gl}=6 ; \mathrm{p}=0,333)$ (Fig. 3).

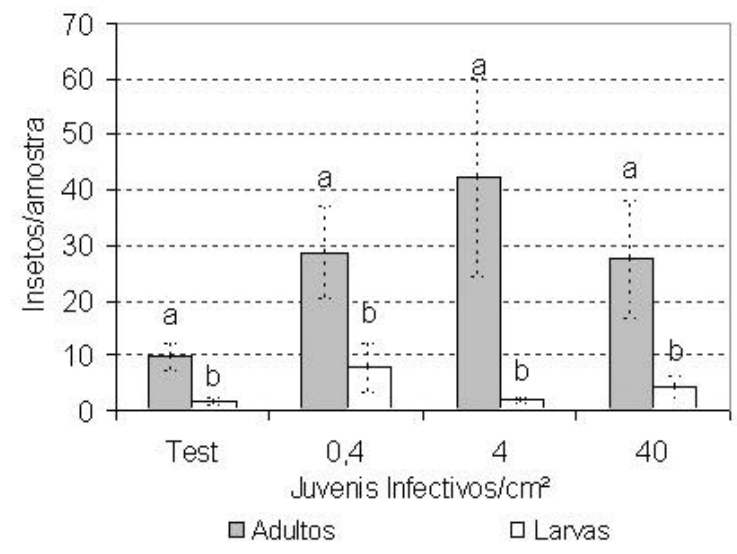

Fig. 1 - População de larvas e adultos por amostra de Alphitobius diaperinus em parcelas localizadas sob comedouros de galpão de frango, antes da aplicação do nematóide Heterorhabditis indica nas áreas selecionadas para os tratamentos com diferentes dosagens. Médias seguidas pela mesma letra não diferem entre si pelo teste de Tukey, a 5\% de probabilidade. Barras = Erro Padrão.
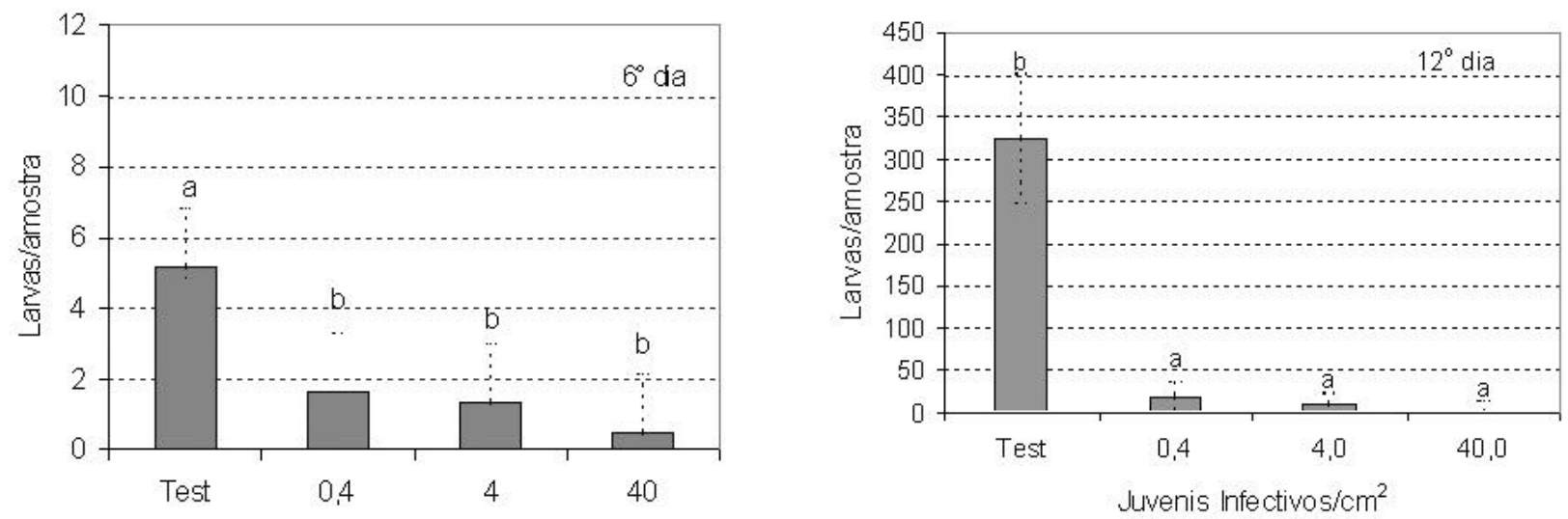

Fig. 2 - População de larvas por amostra de Alphitobius diaperinus em parcelas localizadas sob comedouros de galpão de frango, tratadas com Heterorhabditis indica em diferentes dosagens, após 6 e 12 dias da aplicação do nematóide. Médias seguidas pela mesma letra não diferem entre si pelo teste de Tukey, a 5\% de probabilidade. Barras = Erro Padrão. 

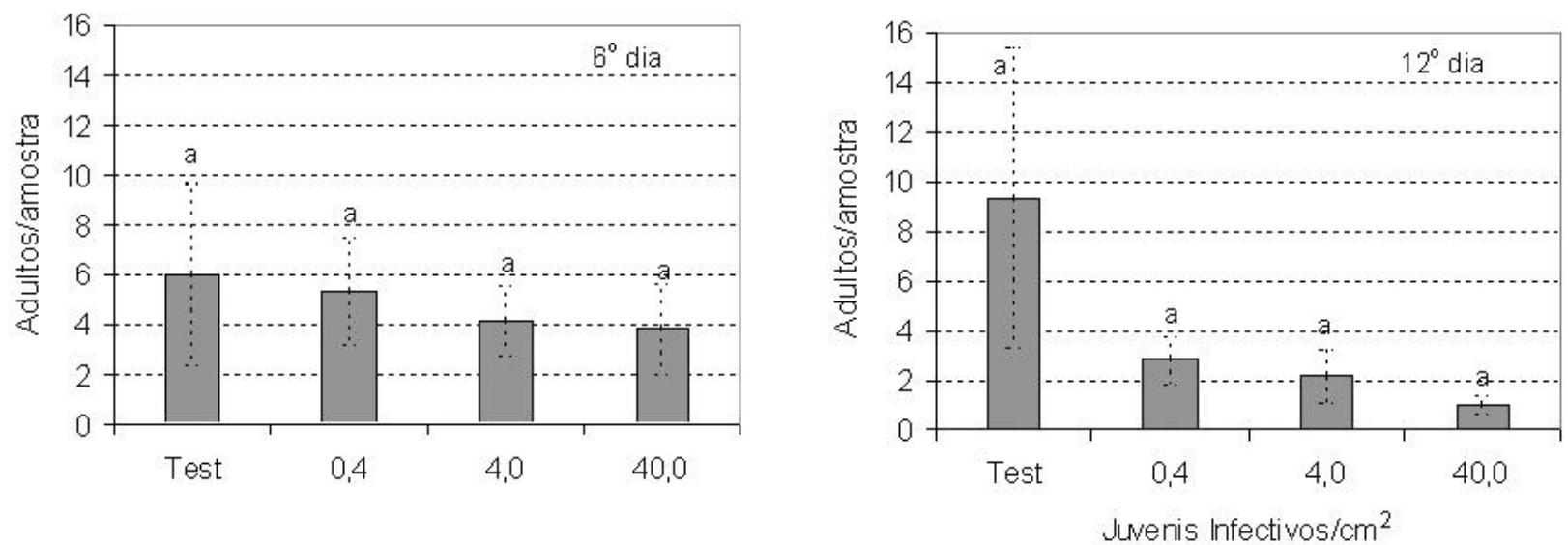

Fig. 3 - População de adultos por amostra de Alphitobius diaperinus em parcelas localizadas sob comedouros de galpão de frango, tratadas com Heterorhabditis indica em diferentes dosagens, após 6 e 12 dias da aplicação do nematóide. Médias seguidas pela mesma letra não diferem entre si pelo teste de Tukey, a 5\% de probabilidade. Barras = Erro Padrão.

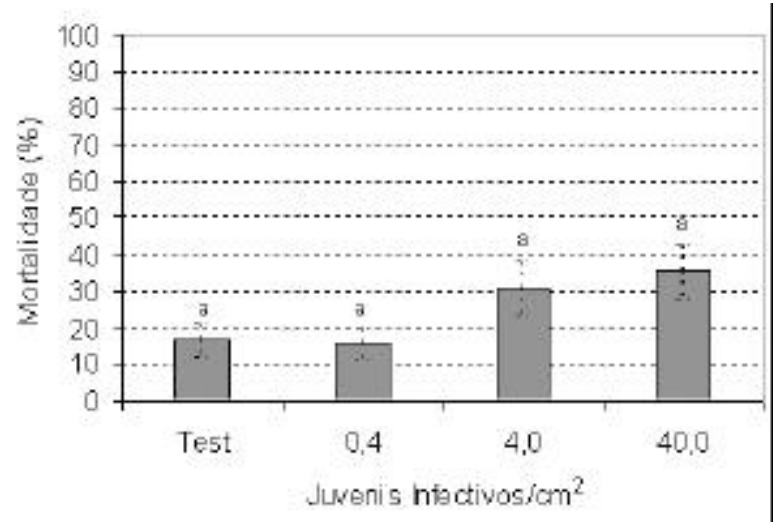

Fig. 4 - Mortalidade de insetos deAlphitobius diaperinusem parcelas formadas no piso de solo batido de galpão de frango, sob serragem, tratadas com Heterorhabditis indica em diferentes dosagens, após 6 e 12 dias da aplicação do nematóide. Médias seguidas pela mesma letra não diferem entre si pelo teste de Tukey, a $5 \%$ de probabilidade. Barras $=$ Erro Padrão.

Oexcelente desempenho do nematóide nas parcelas tratadas, mesmo na menor dosagem (94\% de mortalidade), pode ter sido possibilitado pela preservação da umidade no substrato, decorrente da cobertura formada pelo comedouro apoiado sobre serragem; e também pela presença constante do inseto na tentativa de colonizar o substrato sob comedouros, permitindo a reciclagem do nematóide no hospedeiro e aumento da concentração de inóculo. Sob os comedouros foi encontrado um grande número de insetos mortos, principalmente larvas, todos apresentando uma coloração mais avermelhada que o natural, ou seja, um sintoma característico decorrente da infecção por nematóides do gêneroHeterorhabditis. A persistência dos nematóides entomopatogênicos no ambiente, sob condições favoráveis, tem sido atribuída principalmente à capacidade desses agentes reciclarem-se no hospedeiro, o que ressalta a necessi- dade da presença de insetos suscetíveis na área a ser tratada, procurando obter um controle duradouro da praga alvo (KAYA, 1990).

$\mathrm{Na}$ testemunha do presente estudo, considerando-se que foi encontrada uma média de 325 larvas do inseto no volume de $120 \mathrm{~mL}$ de serragem, poderiam ser gerados sob cada comedouro, com cerca de 3.000 $\mathrm{mL}$ de serragem, até 975.000 insetos. Considerandose que dentro de um galpão de $1.000 \mathrm{~m}^{2}$ são colocados 200 comedouros nos primeiros 15 dias do ciclo do frango, sendo substituídos por 240 a partir desse período, a população do inseto gerada dentro desse galpão até o final do ciclo do frango poderia ser estimada em 429.000.000 indivíduos. Portanto, o presente estudo mostra que a aplicação do nematóide $H$. indica sob comedouros visando eliminar os focos de criação do inseto pode contribuir para o controle dessa praga dentro dos galpões de frango.

Em estudos de laboratório, $S$. feltiae foi mais virulento contra larvas, pupas e adultos de A. diaperinus comparado ao S. glaseri e H. heliothidis (GEDEN et al., 1985). Em teste realizado dentro de galpão avícola, $S$ feltiae foi aplicado sobre o piso de solo antes da distribuição do substrato, persistindo por até sete semanas nesse ambiente com níveis de mortalidade do cascudinho de 63-87\%. Após esse período, o nematóide foi detectado causando baixa mortalidade do inseto, tendo sido afetado principalmente pela elevada temperatura dentro dos galpões, a qual pode ter alcançado até $36^{\circ} \mathrm{C}$ (Geden et al., 1987). Segundo GrAY; JoHSON (1983) S. feltiae é drasticamente afetado em temperaturas acima de $30^{\circ} \mathrm{C}$.

Os nematóides $S$. feltiae e $S$. carpocapsae têm sido mais encontrados em países de clima temperado, com temperaturas mais amenas, enquanto que $H$. bacteriophora e $H$. indica em países tropicais e subtropicais, com climas mais quentes (BURNELL;STOCK, 2000; Hominick, 2002). Portanto, o nematóide H.indica 
IBCB-n05, testado no presente estudo, pode ser mais apropriado do que $S$. feltiae para uso no controle do cascudinho nas condições do Brasil, onde a temperatura interna dentro dos galpões de aviário pode ultrapassar facilmente os $30^{\circ} \mathrm{C}$.

\section{Aplicação no solo batido}

O nematóide $H$. indica IBCB-n05 aplicado sobre o solo, sob a serragem, dentro do galpão de frango, proporcionou controle das larvas adicionadas aos canos de PVC em apenas 15\%, 31\% e 35\% nas dosagens de 0,$4 ; 4,0$ e $40,0 \mathrm{JI} / \mathrm{cm}^{2}$, não havendo diferença significativa entre os tratamentos $(\mathrm{F}=2,799 ; \mathrm{gl}=3 ; \mathrm{p}$ $=0,055$ ) (Fig. 4). Isso sugere uma baixa eficiência desse nematóideno controle do cascudinho quandoaplicado no solo batido. A extrema compactação do solo no piso dos galpões provavelmente reduz a absorção da calda de nematóide aplicada, além de dificultar a locomoção do nematóide e reduzir a aeração do solo. Os elevados níveis de controle obtidos sob os comedouros deveram-se a fatores opostos a esses mencionados, permitidos pela presença de serragem como substrato.

Oprincipal fator que pode prejudicar os nematóides entomopatogênicos de alcançarem o potencial máximo no controle biológico é a sensibilidade desses agentes às variáveis ambientais extremas KAYA; Gaugler, 1993). Assim, os nematóides podem ser afetados em substrato composto de esterco em sistemas de criação de animais confinados devido a possível toxicidade dos componentes do esterco aos juvenis infectantes (JIs), além da ausência de vegetação e de solo adequado nesse ambiente (GEORGIs et al.,1987; TAYLOR et al., 1998). Segundo KAYA;GAUGLER (1993), o uso de práticas de manejo e liberação periódica de nematóides entomopatogênicos podem contribuir para a conservação e proliferação de populações naturais desses agentes e, conseqüentemente, para a supressão de populações de insetos praga.

Os resultados obtidos no presente estudo demonstraram que $H$. indica IBCB-n05 é eficiente para o controle do cascudinho nos focos de reprodução do inseto sob comedouros, quando a base do comedouro é apoiada sobre o substrato tratado e, conseqüentemente, a umidade desse ambiente é preservada. Os valores obtidos nos desvios padrões seriam afetados pelas oscilações na densidade populacional de $A$. diaperinus que ocorre ao longo dos lotes devido a processos migratórios dentro e entre galpões, além de gerações remanescentes que estão protegidas em áreas que não são atingidas pelo controle convencional. Novos estudos são necessários para avaliar o efeito da aplicação desse nematóide sob comedouros, visando a redução populacional do inseto em todo o galpão avícola, e para adaptar a metodologia usada nesse estudo a uma prática de manejo possível de ser adotada pelo avicultor.

\section{CONCLUSÕES}

O nematóide $H$. indica IBCB-n05 pode ser uma alternativa eficiente para o controle do $A$. diaperinus nos focos de reprodução do inseto sob comedouros de galpão de frangos de corte. Esse nematóide não é eficiente no controle do inseto quando aplicado no piso de solo batido sob a serragem.

\section{REFERÊNCIAS}

AXTELL, R.C.; ARENDS, J.J. Ecology and management of arthropod pest of poultry. Annual Review of Entomology, v.35, p.101-126, 1990.

BEDDING, R.A. Large scale production, storage and transport of the insect-parasitic nematodes Neoaplectana spp. and Heterorhabditis spp. Annals Applied Biology, v.104, p.117-120, 1984.

BURNELL, A.M.; STOCK, S.P. Heterorhabditis, Steinernema and their bacterial symbionts - lethal pathogens of insects. Nematology, v.2, n.1, p.31-42, 2000.

CHERNAKI-LEFFER, A.M.M.; BIESDORF, S.M.; ALMEIDA, L.M.; LEFFER, E.V.B.; VIGNE, F. Isolamento de enterobactérias em Alphitobius diaperinus e na cama de aviários no oeste do estado do Paraná, Brasil. Revista Brasileira de Ciência Avícola, v.4, p.1-9, 2002.

DE LA CASA, E.; HAREIN, P.K.; DESHMUKH, D.R.; POMEROY, B.S. Relationship between the lesser mealworm, fowl pox, and Newcastle disease virus in poultry. Journal of Economic Entomology, v.69, p.775-779, 1976.

DE LA CASA, E.; HAREIN, P.K.; POMEROY, B.S. Bacteria and fungi within the lesser mealworm collected from poultry brooder houses. Environmental Entomology, v.1, p.27-30, 1972.

DESPINS, J.L.; AXTELL, R.C.; RIVES, D.V.; GUY, J.S.; FICKEN, M.D. Transmission of enteric pathogens of turkeys by darkling beetle larva (Alphitobius diaperinus). Journal of Applied Poultry Research, v.3, p.6165, 1994.

FERRAZ, L.C.C.B. Nematóides entomopatogênicos. In: ALVES, S.B. (Coord.). Controle microbiano de insetos. São Paulo: Manole, 1986. p.210-221.

GAUGLER, R.; LEWIS, E.; STUART, R.J. Ecology in the service of biological control: the case of entomopathogenic nematodes. Oecologia, v.109, p.483489, 1997. 
GEDEN, C.J.; ARENDS, J.J.; AXTELL, R.C. Field trials of Steinernema feltiae (Nematoda: Steinernematidae) for control of Alphitobius diaperinus (Coleoptera: Tenebrionidae) in commercial broiler and turkey houses. Journal of Economic Entomology, v.80, p.136-141, 1987.

GEDEN, C.J.; AXTELL, R.C.; BROOKs, W.M. Susceptibility of the lesser mealworm, Alphitobius diaperinus (Coleoptera: Tenebrionidae) to the entomogenous nematodes Steinernema feltiae, S. glaseri (Steinernematidae) and Heterorhabditis heliothidis (Heterorhabditidae). Journal of Entomological Science, v.20, p.331-339, 1985.

GEORGIS, B.; MULLENS, A.; MEYER, J.A. Survival and movement of insect parasitic nematodes in poultry manure and their infectivity against Musca domestica. Journal of Nematology, v.19, p.292-295, 1987.

GRAY, P.A.; JOHNSON, D.T. Survival of the nematode Neoaplectana carpocapsae in relation to soil temperature, moisture and time. Journal of the Georgia Entomological Society, v.18, p.454-460, 1983.

HOMINICK, W.M. Biogeography. In: GAUGLER, R. (Ed.). Entomopathogenic nematology. New York: CABI, 2002. p.115-144.

KAYA, H.K. Soil ecology. In: GAUGLER, R.; KAYA, H.K. (Ed.). Entomopathogenic nematodes in biological control. Boca Raton: CRC Press, 1990. p.93-115.

KAYA, H.K.; GAUGLER, R. Entomopathogenic nematodes. Annual Review of Entomology, v.38, p.181-206, 1993.

MCALLISTER, J.C.; STEELMAN, D.D.; SKEELES, J.K.

Reservoir competence of the lesser mealworm (Coleoptera: Tenebrionidae) for Salmonella typhimurium (Eubacteriales: Enterobacteriaceae). Journal of Medical Entomology, v.31, p.369-372, 1994.
MCALLISTER, J.C.; STEELMAN, D.D.; NEWBERRY, L.A.; SKEELES, J.K. Isolation of infections bursal disease virus from the lesser mealworm, Alphitobius diaperinus (Panzer). Poultry Science, v.74, p.45-49, 1995.

MILLER, L.A.; BEDDING, R.A. Field testing of the insect parasitic nematode Neoaplectana bibionis (Nematoda: Steiternematidae) against currant borer moth Synanthedon tipuliformis (Lepidoptera: Sesiidae) in blackcurrants. Entomophaga, v.27, p.109114, 1982.

SAFRIT, R.D.; AXTELL, R.C. Evaluation of sampling methods for darkling beetles (Alphitobius diaperinus) in the litter of turkey and broiler houses. Poultry Science, v.63, p.2368-2375, 1984.

SZALANSKI, A.L.; PALMER, T.W.; MCKAY, T.; STEELMAN, C.D. Infectivity of Steinernema spp. (Nematoda: Steinernematidae) to adult litter beetles, Alphitobius diaperinus (Coleoptera: Tenebrionidae) in the laboratory. Biocontrol Science and Technology, v.14, p.81-85, 2004.

TAYLOR, D.B.; SZALANSKI, A.L.; ADAMS, B.J.; PETERSON II, R.D. Susceptibility of house fly (Diptera: Muscidae) larvae to entomopathogenic nematodes (Rhabditidae, Steinernematidae). Biological Control, v.27, p.1514-1519, 1998.

WESTERMAN, P. The influence of time of storage on performance of the insect parasitic nematode, Heterorhabditis sp. Fundamentals in Applied Nematolology, v.15, p.407-412, 1992.

Recebido em 29/3/07

Aceito em 25/8/08 